\title{
Molecular phylogeny of Squaliformes and first occurrence of bioluminescence in sharks
}

\author{
Nicolas Straube ${ }^{1,2,3^{*}}$, Chenhong Li ${ }^{4}$, Julien M. Claes ${ }^{5}$, Shannon Corrigan² and Gavin J. P. Naylor ${ }^{2}$
}

\begin{abstract}
Background: Squaliform sharks represent approximately $27 \%$ of extant shark diversity, comprising more than 130 species with a predominantly deep-dwelling lifestyle. Many Squaliform species are highly specialized, including some that are bioluminescent, a character that is reported exclusively from Squaliform sharks within Chondrichthyes. The interfamiliar relationships within the order are still not satisfactorily resolved. Herein we estimate the phylogenetic interrelationships of a generic level sampling of "squaloid" sharks and closely related taxa using aligned sequences derived from a targeted gene capture approach. The resulting phylogenetic estimate is further used to evaluate the age of first occurrence of bioluminescence in Squaliformes.
\end{abstract}

Results: Our dataset comprised 172 putative ortholog exon sequences. Phylogenetic estimates result in a fully resolved tree supporting a monophyletic lineage of Squaliformes excluding Echinorhinus. Non-luminous Squalidae are inferred to be the sister to a clade comprising all remaining Squaliform families. Our results suggest that the origin of photophores is coincident with an elevated diversification rate and the splitting of families Dalatiidae, Etmopteridae, Oxynotidae and Somniosidae at the transition of the Lower to the Upper Cretaceous. The presence of luminous organs was confirmed for the Sleeper shark genus Zameus. These results indicate that bioluminescence in sharks is not restricted solely to the families Etmopteridae and Dalatiidae as previously believed.

Conclusions: The sister-clade to non-luminous Squalidae comprises five families. The presence of photophores is reported for extant members of three out of these five families based on results of this study, i.e. Lantern sharks (Etmopteridae), Kitefin sharks (Dalatiidae) and Sleeper sharks (Somniosidae). Our results suggest that the origin of luminous organs arose during the rapid diversification event that gave rise to the extant Squaliform families. These inferences are consistent with the idea of diversification of Squaliform sharks being associated with the emergence of new deep-sea habitats in the Lower Cretaceous, which may have been facilitated by the evolution of

bioluminescence.

\section{Background}

Squaliform sharks constitute a group of highly specialized species with a predominantly deep-dwelling lifestyle. They represent a substantial part of extant shark diversity ( 27 \% [1]) comprising 24 genera and more than 130 described species [2]. Many Squaliform species are bioluminescent, a feature which appears to be exclusive within the Chondrichthyes. Currently, the families Echinorhinidae (Bramble - and Prickly sharks), Squalidae (Dogfish sharks), Centrophoridae (Gulper Sharks), Somniosidae (Sleeper sharks), Oxynotidae (Rough sharks), Dalatiidae (Kitefin sharks), and Etmopteridae (Lantern sharks) are

\footnotetext{
* Correspondence: nicolas.straube@uni-jena.de

${ }^{1}$ Friedrich Schiller Universität Jena, Leutragraben 1, 07743 Jena, Germany

${ }^{2}$ Hollings Marine Laboratory, 331 Fort Johnson Rd, Charleston, SC 29412, USA

Full list of author information is available at the end of the article
}

discussed to form the Squaliformes. However, some previous morphological studies have suggested alternative intergeneric and interfamilial arrangements for the group [2-12].

The phylogenetic placement of Echinorhinidae has remained ambiguous in both morphological and molecular studies, either being included within Squaliformes, considered sister to Squaliformes, or placed in a separate group with Saw sharks (Pristiophoriformes) or Angel sharks (Squatiniformes). Further, recent molecular studies have recovered Squalidae, Centrophoridae, Dalatiidae, and Etmopteridae as monophyletic lineages within the Squaliformes, however, their interfamiliar relationships remain partially unresolved while the family Somniosidae appeared paraphyletic as Oxynotidae cluster within Somniosidae $[2,3,8-24]$. 
All of the molecular data sets examined to date have been based on the analysis of a single or few genes and none have recovered substantial support for branching events at the family level, likely due to limited phylogenetic signal supporting deeper nodes. Phylogenetic analyses based on morphological characters have not yielded consistent results either, e.g. $[9,10]$.

A dataset with strong phylogenetic signal is prerequisite for analyses of the evolution of taxa through time. So far, molecular clock analyses have delivered conflicting results concerning the origin and radiation ages of Squaliform sharks in general and the rise of families in particular [23, 24]. Molecular clocks are best calibrated using information from fossils or from vicariant biogeographic events. Squaliformes are well documented in the fossil record for sharks, which is largely comprised of teeth. Most Squaliform sharks display diagnostic clade specific dentitions pointing to high levels of trophic specialization and conservatism. A number of fossils can therefore be readily assigned to extant lineages such as the Gulper shark genus Centrophorus [25] or the Viper dogfish Trigonognathus [26], without the need to erect distinct genera for extinct forms whose phylogenetic affinities are unclear. According to [25], the fossil record of Squalidae extends back to the Upper Jurassic, while families Centrophoridae, Etmopteridae, Somniosidae, Oxynotidae, and Dalatiidae appeared rather instantaneously at the beginning of the Upper Cretaceous, which has been suggested to be a period of adaptive evolution in response to new ecological opportunities [23, 24]. The oldest Echinorhinid fossils are recorded from the Lower Cretaceous $[25,27]$ the evolution of bioluminescence in Kitefin (Dalatiidae) and Lantern sharks (Etmopteridae) appears to be correlated with the diversification of Squaliform sharks in the deep-sea [23, 24, 28, 29]. Surprisingly, it has not been clear at which point in their evolutionary trajectory, squaliform sharks first acquired photophores. Despite the fact that Shirai [8] had noted that all squaloid sharks except Echinorhinus, Centrophorus, Cirrhigaleus, Deania, Somniosus, and Squalus bear luminous organs, several recent studies suggested that photophores are only present in Etmopteridae and Dalatiidae [2, 23, 30, 31].

In this study, we estimate the phylogenetic interrelationships of Squaliform sharks by applying a gene capture approach that targets a large number of single-copy nuclear exons [32] to a generic level sampling of "squaloid" sharks and closely related taxa [8]. We have used these data in conjunction with fossil calibration data, to estimate times of divergence and diversification rates among the extant lineages examined. We have also explored the potential role that bioluminescence may have had in promoting diversification in these animals, by reconstructing ancestral character states based on the inferred tree and the presence of photophores in extant forms.

\section{Results and discussion}

\section{Molecular phylogeny of Squaliformes}

On average, 200,000 of 352,605 possible basepairs, were sequenced per specimen (Additional file 1: Table S1). Characteristics of the raw dataset are given in Additional file 1: Table S2. Missing data were randomly distributed among specimens resulting in a large amount of incomplete sequences per captured locus and specimen.

MARE [33, 34] detected 174 phylogenetically informative loci in the raw dataset (Additional file 1: Figure S1). Re-blasting the full genome of C. milii against the 174 phylogenetically informative loci resulted in two potentially paraloguous loci (cds 1200 (unknown) and cds 1366 (LRP4)). Excluding these two loci and repeating the maximum likelihood analysis as described above did not affect the inferred tree topology.

Phylogenetic estimates presented herein provide a fully resolved and well-supported molecular hypothesis for the phylogeny of Squaliform sharks. The Maximum Likelihood trees as well as the Bayesian inferences resulting from different types of analyses carried out using RaxML [35] and PhyloBayes 3.3f [36, 37] were broadly congruent in topology except for the phylogenetic placement of Oxynotus. This taxon appears as sister taxon to all somniosid genera except for Somniosus in an analysis of all 1265 loci, but is nested among somniosid genera except for Somniosus in the analyses of the reduced dataset comprising 174 and 172 loci, respectively. The topology used for further analysis is summarized in Fig. 1, and is based on the 172 concatenated nucleotide loci that were selected through the MARE matrix reduction process and re-blasting analysis. The concatenated and aligned 172 nucleotide loci are deposited in the Dryad data repository [38] (Additional file 1: Tables S3 and S4, Figures S3 to S6).

This phylogenetic estimate reveals two major clades: the Squaliformes excluding Echinorhinidae and a clade containing Squatina, Pristiophoriformes, and Echinorhinus (Fig. 1). Within this clade, Echinorhinus is sister to Squatina and Pristiophoriformes. Results suggest that Echinorhinidae are not Squaliform sharks, but are the sister group to Angel- (Squatiniformes) and Saw sharks (Pristiophoriformes), as previously suggested by the analysis of mitochondrial data [21]. Therefore, Squaliformes form a monophyletic group only, if Echinorhinus is excluded. This study does not support results from [24], suggesting Echinorhinus being the sistergroup to the remaining Squaliform lineages. The node time estimation for the Echinorhinus lineage suggests an Upper Jurassic splitting of the extant Echinorhinus lineage and the Squatina plus Pristiophoriformes clade. This dates the Echinorhinus 


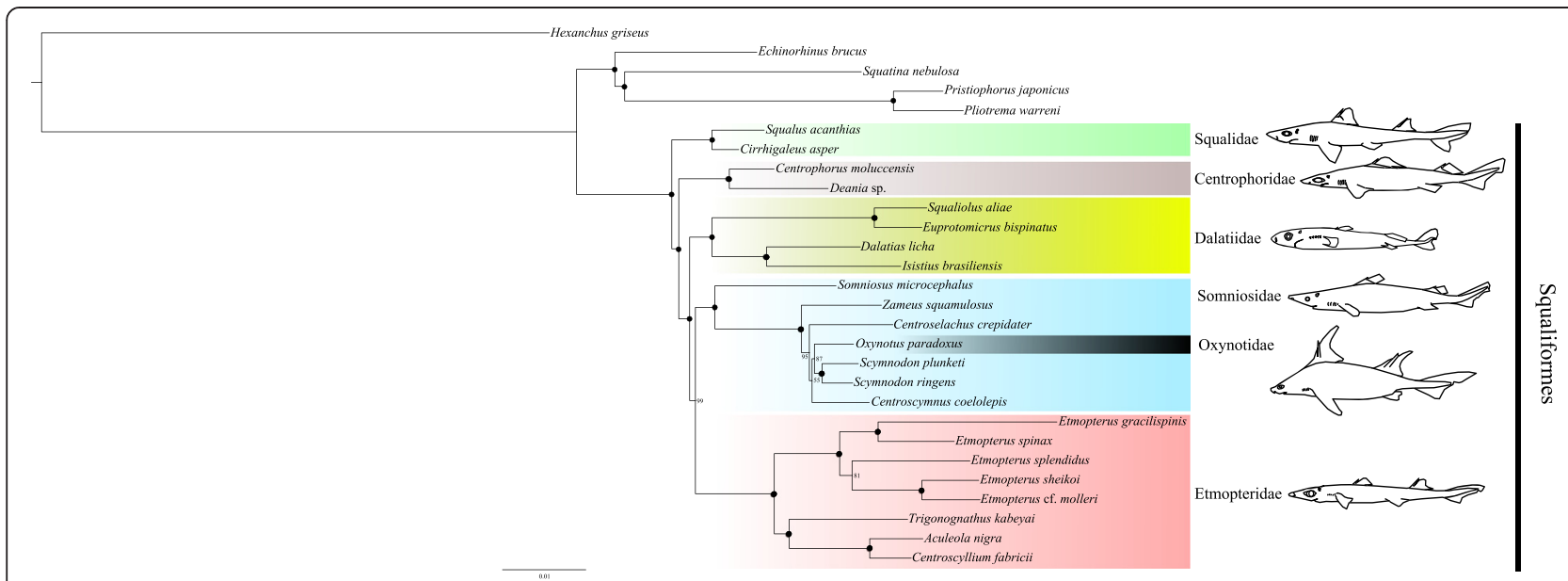

Fig. 1 Maximum likelihood phylogenetic estimate of squalomorph sharks based on gene capture data of 172 nucleotide loci under a GTR + Gamma model using RAxML [35] partitioned into two sets, 1st and 2nd codon position as well as 3rd codon only. Analyzed specimens are listed in Additional file 1: Table S1. Nodes marked with black dots indicate $100 \%$ bootstrap support and a posterior probability of 1 assessed in the Bayesian inference from the Phylobayes 3 analysis applying the CAT model $[36,37,64]$. Tree rooted midpoint, no outgroup defined.

lineage older than anticipated from the fossil record, which reports the oldest echinorhinid fossil from the early Cretaceous (Hauterivian) of southeastern France [27], while the oldest squatinids already appear in the Upper Jurassic [25].

Within the Squaliform clade, the first split separates Squalidae from the remaining families Centrophoridae, Etmopteridae, Dalatiidae, Somniosidae, and Oxynotidae. The genera Squalus and Cirrhigaleus appear as sister taxa. Centrophoridae split from Etmopteridae, Dalatiidae, Somniosidae, and Oxynotidae, where genera Deania and Centrophorus are sister. Dalatiidae are sister to a clade comprising Etmopteridae, Somniosidae, and Oxynotidae. There are two clades within the dalatiids, one comprising the Isistius and Dalatias lineages, the other Squaliolus and Euprotomicrus. As shown in Fig. 1, Somniosidae sensu stricto form two clearly distinct lineages that are sister to each other, one containing the genus Somniosus (Fig. 1), the other lineage contains all other remaining somniosid genera. Oxynotidae cluster within Somniosidae (Fig. 1). Within Etmopteridae, Trigonognathus is sister to a clade comprising Aculeola and Centroscyllium. Etmopterus is sister to this previously described clade forming four distinct lineages representing the subclades described in [23].

Oxynotus is inferred to be nested within Somniosidae, rendering the family Somniosidae paraphyletic (Fig. 1) in the current study. This result is repeatedly recovered in phylogenetic estimates based on DNA sequence data (both mitochondrial and nuclear) [19-24]. Given the consistency of the inferences from molecular data, it would be interesting to see if any anatomical features also support the link between Oxynotidae and Somniosidae. Oxynotus clusters with a group of otherwise morphologically similar species of somniosids, i.e. along with Zameus,
Centroselachus, Scymnodon, and Centroscymnus. Our molecular results show that all five genera are closely related (Fig. 1). This is especially evident when comparing intergeneric diversity within Somniosidae with the large intrageneric sequence differences evident within the genus Etmopterus (Fig. 1). Moreover, there are limited morphological characters that can be used to differentiate some of these taxa $[8,39]$. Together these results imply that assigning separate generic status to some species within Somniosidae may be an overrepresentation of the true diversity within the family.

\section{Occurrence and significance of bioluminescence in Squaliform sharks}

The Bayesian inference estimated with BEAST $[40,41]$ is widely congruent with the maximum likelihood phylogeny (Fig. 1, Additional file 1: Figures S3 to S6).

Results from node time estimates based on 172 loci support a squaliform shark radiation beginning in the Lower Cretaceous and continuing through to the Upper Cretaceous (Table 1). A sister-group relationship of nonluminous Squalidae with a clade comprising all other Squaliformes is strongly supported as the most ancient split of extant Squaliformes (Table 1) and is consistent with the fossil record $[25,29]$. Centrophoridae rise in the Lower Cretaceous, followed by the splitting of Dalatiidae, Somniosidae, Oxynotidae and Etmopteridae, which also aligns with the sequence of appearance of these taxa in the fossil record. However, $95 \%$ confidence intervals are large, preventing exact estimates (Table 1). A second radiation occurred within Etmopteridae and Somniosidae in the Upper Cretaceous and the beginning of the Palaeocene (Table 1), again, a time 
Table 1 Node time estimates for major splitting events

\begin{tabular}{|c|c|c|c|c|}
\hline $\mathrm{Nr}$. & Node & Node age & $95 \% \mathrm{HPD}$ & Series/Epoch \\
\hline 1 & Squalomorphii & 202.8 & $190-241.32$ & Middle Triassic to Lower Jurassic \\
\hline 2 & $\begin{array}{l}\text { Splitting of Squaliformes from the clade } \\
\text { comprising Echinorhinus, Squatina, } \\
\text { Pliotrema \& Pristiophorus }\end{array}$ & 177.34 & $153.85-203.99$ & Upper Triassic to Upper Jurassic \\
\hline 3 & $\begin{array}{l}\text { Clade comprising Echinorhinus, Squatina, } \\
\text { Pliotrema \& Pristiophorus }\end{array}$ & 147.59 & $145-156.1$ & Upper Jurassic \\
\hline 4 & Radiation Squaliformes & 132.86 & $130-143.18$ & Lower Cretaceous \\
\hline 5 & $\begin{array}{l}\text { Split Centrophoridae from Dalatiidae, } \\
\text { Etmopteridae, Oxynotidae \& Somniosidae }\end{array}$ & 126.68 & $113.94-137.88$ & Lower Cretaceous \\
\hline 6 & $\begin{array}{l}\text { Split Dalatiidae from Etmopteridae, Oxynotidae \& } \\
\text { Somniosidae }\end{array}$ & 116.1 & $99.2-131.01$ & Transition Lower to Upper Cretaceous \\
\hline 7 & Split Etmopteridae from Somniosidae \& Oxynotidae & 110.51 & $92.81-124.88$ & Transition Lower to Upper Cretaceous \\
\hline 8 & Split Centrophorus from Deania & 90.82 & $89-96.84$ & Upper Cretaceous \\
\hline 9 & $\begin{array}{l}\text { Split Somniosus from Oxynotidae \& remaining } \\
\text { Somniosidae }\end{array}$ & 92.29 & $64.8-114.49$ & Upper Cretaceous \\
\hline 10 & Radiation Dalatiidae & 83.57 & $65-105.4$ & Upper Cretaceous \\
\hline 11 & Radiation Etmopteridae & 77.15 & $65-90.66$ & Upper Cretaceous \\
\hline 12 & Radiation Etmopterus & 60.38 & $46.28-74.64$ & Upper Cretaceous to Palaeocene \\
\hline 13 & $\begin{array}{l}\text { Split Trigonognathus from Aculeola \& } \\
\text { Centroscyllium }\end{array}$ & 61.5 & $44.5-76.86$ & Upper Cretaceous to Palaeocene \\
\hline 14 & $\begin{array}{l}\text { Radiation Somniosidae excluding } \\
\text { Somniosus }\end{array}$ & 43.4 & $24.46-63.94$ & Eocene \\
\hline 15 & Split Oxynotus from Scymnodon & 28.91 & $15.32-47.11$ & Oligocene \\
\hline
\end{tabular}

period characterized by profound changes in the marine environment including the deep-sea. As discussed in [23], the Eocene recovery phase and the admixing of the deep-sea by the establishment of the circumantarctic current at the beginning of the Oligocene, may have set the stage for this second radiation.

Novel ecological opportunities after oceanic anoxic events have been hypothesized to trigger adaptive radiation of sharks in deep-water environments in the Lower Cretaceous [10, 24]. Results from the MEDUSA [42, 43] analysis indicate a background diversification rate $r=0.02$. An elevated diversification rate was detected for families Etmopteridae, Dalatiidae, Oxynotidae and Somniosidae, $(r=0.05)$ and the radiation of the species-rich genus Squalus ( $r=0.15$, Fig. 2).

We reconstructed ancestral character states in order to test the hypothesis that bioluminescence evolved in conjunction with the diversification of the Dalatiidae, Etmopteridae, Oxynotidae and Somniosidae. In the first analysis, we coded Dalatiidae and Etmopteridae as luminescent. Results from this analysis indicated that the common ancestor of families Dalatiidae, Etmopteridae, Oxynotidae, and Somniosidae was already likely carrying luminous organs. Interestingly, Somniosidae have been widely accepted as non-luminous [2, 23, 30, 31, 44]. However, Shirai [8] suggested that all Somniosidae are luminescent except for the genus Somniosus, which may have secondarily lost the ability to produce light.

We reviewed the presence of photophores in Somniosidae and Oxynotidae, by inspecting the ventral surface area of several specimens housed in zoological collections. The inspection of skin samples from Zameus squamulosus revealed clear presence of epidermal photophores (mean diameter $=41.75 \pm 1.95 \mu \mathrm{m}$, density $=26$ units $\mathrm{mm}^{-2}$, PAP $=3.74 \%$ ) in this taxon (Fig. 3). The majority of these organs appeared to be ring-shaped and covered with translucent dermal denticles. Zameus photophores are visible as open dark circular plaques, typical of functional photophores that are capable of producing light. Indeed, this morphology is typically adopted by dalatiid and etmopterid photophores while glowing [44-48]; the translucent nature of $Z$. squamulosus scales would allow efficient transmission of underlying photophore light, similar to the observation of light transmission through the ventral scales of opisthoproctid fishes [49] or through the dorsal finspines of the velvet belly lanternshark, Etmopterus spinax [50].

Morphological data presented herein provide clear evidence that functional photophores are present within Somniosidae, at least within the genus Zameus (Fig. 3). All other inspected specimens showed no evidence of epidermal photophores. In light of this, the ancestral 


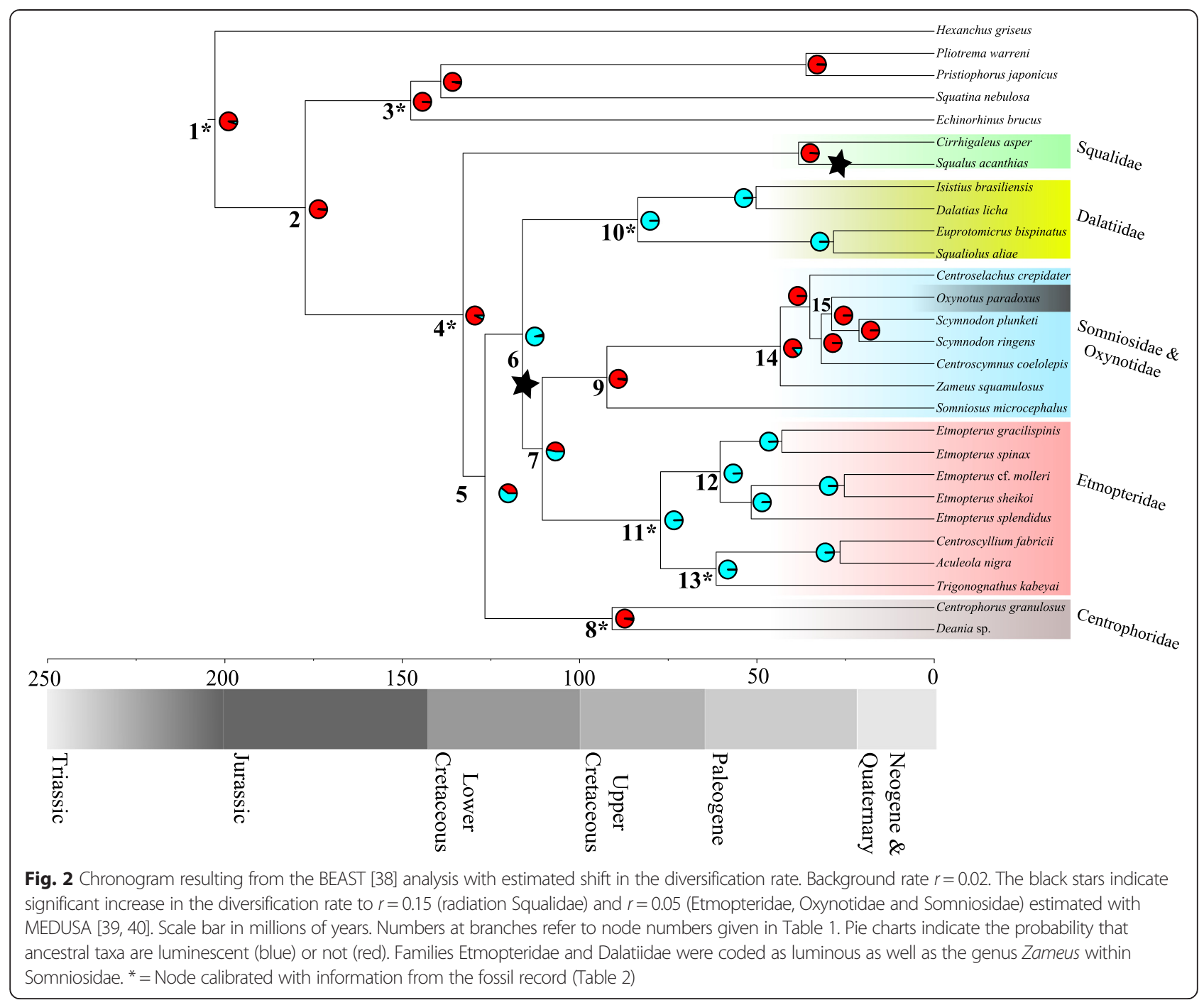

character state reconstruction was repeated incorporating results from the inspection of skin samples, i.e. coding the genus Zameus in addition to Etmopteridae and Dalatiidae as luminescent. Results from this analysis further increased the likelihood that the common ancestor of Dalatiidae, Etmopteridae and Somniosidae was luminescent (Fig. 2). The common ancestor of Centrophoridae, Etmopteridae, Dalatiidae, Oxynotidae, and Somniosidae is also implied to have been luminescent, but the likelihood is less compelling. A further analysis following [8] coding somniosid genera Centroselachus, Centroscymnus, Scymnodon, and Zameus as luminous further increases the likelihood so that the common ancestor of all Squaliformes except Squalidae may already have been luminescent (Additional file 1: Figure S8). This indicates that extant Centrophoridae may have secondarily lost their ability to emit light, i.e. that luminous organs may have already been present at the branching event giving rise to families Centrophoridae, Dalatiidae, Etmopteridae, Somniosidae, and Oxynotidae (Fig. 2). This suggests that luminescence evolved along and facilitated the Squaliform deep-sea radiation - a scenario that would be consistent with the elevated diversification rate detected for Etmopteridae, Somniosidae, and Oxynotidae. (Fig. 2, Additional file 1: Figures S8 and S9). We speculate that the common ancestor of families Dalatiidae, Etmopteridae, Oxynotidae, and Somniosidae was luminescent and used this to enhance camouflage by counterillumination as this is assumed to be the most basal function of shark bioluminescence [23, 28, 45, 47].

The occurrence of bioluminescence within the family Somniosidae is not surprising as especially the smaller sized genera (Centroselachus, Centroscymnus, Scymnodon, and Zameus) occur in sympatry with other luminous sharks such as etmopterids and dalatiids as well as a number of other luminescent deep-sea taxa including myctophid fishes 


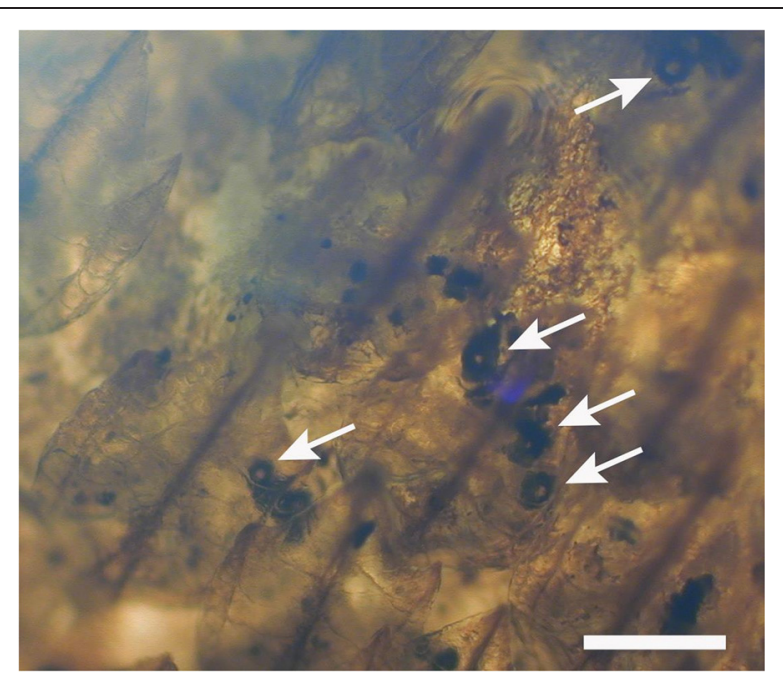

Fig. 3 Microscopic photograph of an excised ventral skin patch of Zameus squamulosus (ZSM30966). Arrows indicate photophores in open state. Scale bar indicates $200 \mu \mathrm{m}$

which interestingly were estimated to have radiated in a similar time window [51]. Results presented here lend further support to the hypothesis that bioluminescence in sharks evolved only once [29, 47]. Work in progress will allow identifying all luminous taxa within the family Somniosidae.

\section{Conclusions}

Our findings provide insights into the phylogeny of Squaliform sharks as well as the evolution of bioluminescence in the group. The radiation is estimated to have started in the Lower Cretaceous and continued through to the Upper Cretaceous. The initial elevated diversification rate is correlated with the likely first occurrence of luminous organs in sharks. The presence of photophores was confirmed for the genus Zameus in the family Somniosidae, implying that bioluminescence in sharks is not restricted to families Etmopteridae and Dalatiidae as is widely believed.

\section{Methods}

\section{Targeted gene capturing}

To ensure correct sample IDs of target samples, we either used genomic DNA of specimens which were previously analyzed in $[21,23,52,53]$ or generated NADH2 sequences as described in [22] and compared to the samples analysed in $[21,52,53]$. In the latter case, genomic DNA was extracted from collection material (tissues in GJPN tissue collection) already used in previous studies and stored in $95 \%$ ethanol. Genomic DNA was obtained using the Promega Wizard DNA Purification System (Fisher Scientific). Total amounts of DNA were measured using a Qbit $^{\oplus}$ Fluorometer (Life Technologies).
Subsequently, genomic DNA of the 28 target samples was sheared to approximately 500 bp using a Covaris ${ }^{\circ}$ Sonicator. Sheared samples were used to prepare Illumina sequencing libraries following the protocol provided in [32]. See Additional file 1: Table S1 for an overview of samples analysed.

We designed custom RNA bait libraries for targeting putatively single-copy orthologous genes based on sequences derived from seven shark species in [32], i.e. Chlamydoselachus anguineus, Etmopterus joungi, Isurus oxyrinchus, Orectolobus halei, Carcharhinus amblyrhynchos, Heterodontus portusjacksoni, and Squatina nebulosa. Each bait library comprised a pooled series of $120 \mathrm{bp}$ baits designed for each target locus. As in [32], a 60 bp tiled overlap across baits was used to generate two-fold redundancy coverage for each target gene. When the length of the target gene was less than $120 \mathrm{bp}$, the sequence was extended in length to $120 \mathrm{bp}$ by adding thymine nucleotides. The baits were manufactured by MyCroarray ${ }^{\circ}$ (Ann Arbor, MI, USA).

Thereafter, gene capture was conducted by hybridization of target DNA to the baits. After hybridization, unbound and non-target DNA was washed away [32]. The remaining library was enriched for target loci and was re-amplified to incorporate sample specific indices. Samples were pooled in equimolar ratios for sequencing. The pooled product was quantified using the CFX Connect Real-Time PCR system (Bio-Rad, Hercules, CA). Pooled sample was diluted to 8 pM and used for paired-end $150 \mathrm{bp}$ or $250 \mathrm{bp}$ sequencing on an Illumina MiSeq sequencing instrument (Illumina, Inc, San Diego, CA). Sequence reads associated with each sample were identified by their respective indices.

\section{Alignment reconstruction of gene capture data}

Adapters were trimmed from sequence reads using Trimgalore v0.3.7. $[54,55]$ and assembled de novo using ABySS ver1.3.5. [56] with a k-mer of 64. Assembled contigs were assigned to core ortholog groups using HaMStR [57]. The core ortholog database consisted of profile hidden Markov models of orthologous sequence groups from model vertebrates [32]. Any sequence that matched a core-ortholog pHMM was provisionally assigned to the corresponding orthologous group. In order to be retained in the final matrix, provisional sequence hits also had to satisfy a reciprocal best BLAST criterion when compared to Callorhinchus milii as the reference taxon. Orthologous exons were trimmed from non-target intron information and aligned with Mafft $[58,59]$. Finally, all loci were concatenated.

\section{Data analysis and phylogenetic reconstruction}

Maximum likelihood (ML) trees were estimated using RAxML GUI [33, 60]. The initial ML analysis used the 
complete concatenated dataset (i.e. 1265 loci and 28 taxa) under GTR GAMMA using different partitioning schemes (Additional file 1: Table S4) using the automatic halt for bootstrapping [61]. Squalomorph sharks are widely accepted as monophyletic [8, 19-22]. Within Squalomorphs, Hexanchiformes are considered to form the most basal lineage $[8,20-22]$, therefore, Hexanchus griseus was chosen as the outgroup taxon.

Subsequently, MARE ver.1.2 [33, 34] was used to examine the dataset for phylogenetically informative sites and taxa. MARE [33, 34] was designed to identify the most phylogenetically informative subset of sites contained in phylogenomic data sets. It is especially well-suited to analysis of data sets with a high proportion of missing data. MARE [33, 34] identified 174 maximally informative loci for our data set reducing the maximal total sequence length per specimen from 352,605 bp to 73,925 bp (Additional file 1: Figure S1).

As a further scan for paraloguous sequences, we reblasted the full genome of Callorhinchus milii against the remaining 174 loci to check, if each sequence has only a single hit in the C. milii genome using customized Perl scripts (Additional file 1).

The reduced nuclear dataset comprising 172 concatenated nucleotide loci is deposited at [38]. This data was analysed as described for the full dataset and additionally RaxML GUI $[35,60]$ was applied to the amino acid alignment comprising infomative loci using the best partitioning scheme suggested by PartitionFinder Protein v1.1.1 [62, 63]. Further, the reduced 172 loci DNA sequence data alignment was analysed with PartitionFinder v1.1.1 to look for best fitting partition schemes and models of molecular evolution $[62,63]$ to determine if different partition types influence the tree topology. We used the rcluster option with a rcluster percentage of 10 [63] for the analysis. The Bayesian mixture model CAT [64] implemented in PhyloBayes 3.3f [36, 37] was used on the concatenated 172 amino acid alignment to partition sites into different rate categories using nonparametric modeling of site specific effects. This allowed us a topological comparison to the ML analysis under GTR GAMMA [65]. Four independent chains were run in parallel. The tracefiles and treelists of all four chains were used to check for convergence. The analysis was stopped with a maximum difference of 0.16 and effective sample sizes exceeding 100, with the exception of the allocent statistic (see Additional file 1). A majority rule consensus tree was computed from 12997 input trees from each chain with a burn-in of 1000 trees and analyzing every second tree of the pooled trees. The consensus tree was rooted midpoint.

See Additional file 1: Table S4 and Figures S3 to S7 for a summary of partitioning schemes and phylogenetic analyses conducted. To ensure that the choice of a single outgroup does not have a negative effect such as long branch attraction on our phylogenetic analysis, we performed analysis not defining an outgroup, defining different outgroups as well as deleting Hexanchus griseus from the dataset and re-computing a phylogenetic estimate without defining an outgroup taxon (Additional file 1: Figure S2).

\section{Node time estimation and diversification rate}

BEAST ver. 1.8.0 [40, 41] was used to estimate node ages from the MARE [33, 34] reduced nucleotide alignment excluding cds 1200 and 1366 and partitioned into two partitions, the first comprising codon positions 1 and 2, the second codon position 3 applying the GTR Gamma model. XML files were created in BEAUTi [41]. The analysis assumed a relaxed molecular clock approach under an uncorrelated lognormal model [40]. The Yule speciation process was implemented assuming a constant speciation rate per lineage as tree prior. We calibrated our phylogenetic tree using calibration points deployed from the fossil record of Squalomorph sharks (Table 2). The root age calibration should reflect the age of origin of Squalomorph sharks. The discussion of the age of Squalomorphs is enduring and contingent on the discovery of new fossil information [25]. Here, we assumed the origin of Squalomorphii, i.e. our root age, to have occurred between 190 and 279 Ma based on distinct Hexanchoid teeth from the Lower Jurassic as minimum age and the fossil appearance of Protracodus, the oldest tooth fossils that carry morphological characters of euselachians as a soft upper bound. We would like to point out that we consider this calibration as a minimum age calibration for the crown Squalomorphii following [25, 66] even though the chondrichthyan stem may be as old as, or even older than, the Middle Ordovician [67].

The clade comprising Echinorhinidae, Pristiophoriformes Pliotrema and Pristiophorus as well as Squatina was assumed to vary in age between 145 to $163 \mathrm{Ma}$ (Upper Jurassic) based on articulated fossils of Squatinids at the

Table 2 Calibration points used for node time estimates of squaloid sharks

\begin{tabular}{|c|c|c|c|c|}
\hline & Taxon set & $\begin{array}{l}\text { Minimum } \\
\text { age (Ma) }\end{array}$ & $\begin{array}{l}\text { Soft upper } \\
\text { bound (Ma) }\end{array}$ & Citation \\
\hline Cp 1 & Root age (Squalomorphii) & 190 & 279 & {$[71]$} \\
\hline $\mathrm{Cp} 2$ & Squaliformes & 130 & 163 & {$[25]$} \\
\hline $\mathrm{Cp} 3$ & $\begin{array}{l}\text { Echinorhinidae, Squatinidae \& } \\
\text { Pristiophoridae }\end{array}$ & 145 & 163 & {$[25]$} \\
\hline Cp 4 & Centrophoridae & 89 & 100 & [72] \\
\hline Cp 5 & Dalatiidae & 65 & 100 & {$[25]$} \\
\hline Cp 6 & Etmopteridae & 65 & 100 & {$[25]$} \\
\hline $\mathrm{Cp} 7$ & $\begin{array}{l}\text { Trigonognathus, Aculeola \& } \\
\text { Centroscyllium }\end{array}$ & 44.5 & 100 & {$[26]$} \\
\hline
\end{tabular}


lower and Echinorhinus sp. teeth at the upper end of the time frame [25, 27]. The minimum age of Squaliformes was calibrated to 130 Ma based on the fossil taxon Protosqualus with a soft upper bound at $163 \mathrm{Ma}$ allowing for the possibility that Squaliform sharks were already present in the Upper Jurassic [25]. Squaliform family-level diversity is assumed to have originated in the late Mesozoic (Upper Cretaceous) [23], while most extant genera likely originated in the Cenozoic. Fossil evidence was used to calibrate the minimum age of Centrophoridae, Etmopteridae and Dalatiidae to be $65 \mathrm{Ma}$ (C/T boundary) with a soft upper bound of $100 \mathrm{Ma}$ (beginning of the Upper Cretaceous). Further, the clade comprising Trigonognathus, Aculeola, and Centroscyllium was assumed to be of minimum age of $45 \mathrm{Ma}$ and a lower bound of $100 \mathrm{Ma}$ based on the fossil record of Trigonognathus virginiae [26] and the age estimate of extant Etmopteridae in [24].

All analyses assumed an exponential prior distribution for calibration points. Three independent runs were performed with a Markov Chain lasting 90 million generations each, sampling trees every 1000 generations. One run included the maximum likelihood inferred tree with the highest likelihood as a newick formatted starting tree. This BEAST input file is deposited in the Dryad data repository [36]. Combined log files were analyzed in Tracer v.1.6 [68] to check, if the effective sample sizes (ESS) of parameters represent the posterior distribution adequately; further trace and density plots were checked for convergence of the MCMC and posterior probability distributions in different runs. After defining a burn-in of $25 \%$ of all sampled trees in each run, TreeAnnotator [40] was used to create a consensus tree which was visualized in FigTree v.1.4.0 [69].

We used the $\mathrm{R}$ [70] module MEDUSA (modeling evolutionary diversification using stepwise AIC) [43] implemented in the GEIGER package [42] to estimate changes in the diversification rate based on the consensus chronogram attained from the BEAST [41] analysis. Species richness values were obtained from [1].

\section{Ancestral bioluminescence within Squaliformes}

Ancestral character states of bioluminescence were reconstructed using Maximum Likelihood estimates implemented in the $\mathrm{R}$ [70] package GEIGER [42] and are based on the chronogram attained from the BEAST [41] analyses. In a first analysis, we coded only Dalatiidae and Etmopteridae as luminescent. Results from this analysis indicated that the common ancestor of families Dalatiidae, Etmopteridae, and Somniosidae was already likely luminescent. As an empirical test of this idea, we subsequently inspected the ventral surface area of Somniosidae and Oxynotidae specimens from the Bavarian
State Collection of Zoology -Centroselachus crepidater (ZSM30842), Centroscymnus owstonii (ZSM36725), Oxynotus bruniensis (ZSM30862), and Zameus squamulosus (ZSM30966) - and the Zoological Museum Hamburg Somniosus microcephalus (ZMH 123507), S. rostratus (ZMH 25751), Centroscymnus coelolepis (ZMH 119748), Centroscymnus owstonii (ZMH 104894), Centroselachus crepidater (ZMH 103185), Scymnodalatias sp. (ZMH 122774), Zameus squamulosus (ZMH 120262; $\mathrm{ZMH}$ 120485). When pigmentation was apparent, a $1 \mathrm{~cm}^{2}$ skin patch was excised from the ventral surface of the specimen and observed under a binocular microscope (Leica MZ6, Wetzlar, Germany). If photophores were observed, a picture was taken and analysed in Image J v. 1.46 using a random $1 \times 1 \mathrm{~mm}$ counting frame to estimate photophore mean diameter, photophore density and proportion of the skin surface area occupied by photophores (PAP) following the method of [28]. Thereafter, the ancestral character state reconstruction was repeated incorporating results from the inspected skin samples in a second analysis, and incorporating information on presence of luminous organs in somniosids following [8] in a third test. See Additional file 1 for documentation on $\mathrm{R}$ scripts used and the different photophore presence/ absence matrix (Additional file 1: Table S6).

\section{Availability of supporting data}

The data sets supporting the results of this article are available in the Dryad repository, http://datadryad.org/ review?doi=doi:10.5061/dryad.n3581. See also Additional file 1.

\section{Additional file}

Additional file 1: Documentation of conducted analyses.

(PDF $1710 \mathrm{~kb}$ )

\section{Competing interests}

The authors declare that they have no competing interests.

\section{Authors' contributions}

Laboratory work was carried out by NS, CL, and SC. NS analyzed the data and wrote the manuscript; GJPN supervised the study and drafted the manuscript. SC helped with manuscript writing. JMC carried out all lab work related to photophore identification in Somniosidae and wrote the related text parts of the manuscript. All authors read and approved the final version of the manuscript.

\section{Acknowledgements}

This project was funded by the National Science Foundation (NSF), grant "Jaws and Backbone: Chondrichthyan Phylogeny and a Spine for the Vertebrate Tree of Life"; DEB-01132229 to GJPN. JMC is a postdoctoral researcher at Fonds National de la Recherche Scientifique (FNRS, Belgium). We would like to express our sincere thanks to Ting Kuang (Shanghai Ocean University, Shanghai) for her help with re-blasting, Elisabeth Rochel (CofC, Charleston) for help in the lab, Thomas Fussel (CofC, Charleston) and Adam Bazinet (University of Maryland, College Park) for analysis pipeline programming. Alan Pradel (MNHN, Paris), Jürgen Pollerspöck, Ulrich K Schliewen (ZSM, Munich), Alexander Cerwenka (ZSM, 
Munich), and Frederic Schedel (ZSM, Munich) are thanked for fruitful discussions. We would further like to acknowledge institutional support at the Bavarian State Collection of Zoology (ZSM, Munich, Dirk Neumann) as well as the Zoological Museum Hamburg (ZMH, Hamburg, Simon Weigmann).Two anonymous reviewers are acknowledged for their constructive criticism.

\section{Author details}

${ }^{1}$ Friedrich Schiller Universität Jena, Leutragraben 1, 07743 Jena, Germany. ${ }^{2}$ Hollings Marine Laboratory, 331 Fort Johnson Rd, Charleston, SC 29412, USA. ${ }^{3}$ Bavarian State Collection of Zoology, Münchhausenstraße 21, 81247 Munich, Germany. ${ }^{4}$ Key Laboratory of Exploration and Utilization of Aquatic Genetic Resources, Shanghai Ocean University, Ministry of Education, Shanghai 201306, China. ${ }^{5}$ Marine Biology Laboratory, Earth and Life Institute, Université catholique de Louvain, Kellner building, 3 Place Croix du Sud - bte L7.06.04, 1348 Louvain-la-Neuve, Belgium.

\section{Received: 13 January 2015 Accepted: 4 August 2015 Published online: 16 August 2015}

\section{References}

1. Pollerspöck J, Straube N: www.shark-references.com, World Wide Web electronic publication, 2015

2. Ebert DA, Fowler S, Compagno LJV. Sharks of the World - A Fully Illustrated Guide. Plymouth: Wild Nature Press; 2013

3. Compagno LJV. Interrelationships of Living Elasmobranchs. In: Greenwood PH, editor. Interrelationships of Fishes. London: Academic; 1973. p. 15-61.

4. Compagno LJV. Phyletic relationships of living sharks and rays. Am Zool. 1977;17:303-22.

5. Maisey JG. An evaluation of jaw suspension in sharks. Am Mus Novi. 1980;2706:1-17.

6. Maisey JG. Chondrichthyan phylogeny: a look at the evidence. J Vertebr Paleontol. 1984;4(3):359-71. doi:10.1080/ 02724634.1984.10012015.

7. Maisey JG. Higher elasmobranch phylogeny and biostratigraphy. Zool J Linnean Soc. 1984;82(1-2):33-54. doi:10.1111/j.1096-3642.1984.tb00534.x.

8. Shirai S. Squalean Phylogeny and Related Taxa. Hokkaido: University Press; 1992.

9. Shirai S. Phylogenetic Interrelationships of Neoselachians (Chondrichthyes, Euselachii). In: Stiassny ML, Parenti LR, Johnson GD, editors. Interrelationships of Fishes. San Diego: Academic; 1996. p. 9-34.

10. Adnet S, Cappetta H. A palaeontological and phylogenetical analysis of squaliform sharks (Chondrichthyes: Squaliformes) based on dental characters. Lethaia. 2001;34:234-48.

11. de Carvalho MR. Higher-Level Elasmobranch Phylogeny, Basal Squaleans, and Paraphyly. In: Stiassny MLJ, Parenti LR, Johnson GD, editors. Interrelationships of Fishes. San Diego: Academic; 1996. p. 35-62.

12. de Carvalho MR, Maisey JG. The Phylogenetic Relationship of the Late Jurassic Shark Protospinax Woodward 1919 (Chondrichthyes: Elasmobranchii). In: Arratia G, Viohl G, editors. Mesozoic Fishes - Systematics and Paleoecology. München: Friedrich Pfeil Verlag; 1996. p. 9-46.

13. Bass AJ, Compagno LV, Heemstra PC. Squalidae. In: Smith MM, Heemstra PC, editors. Smith's Sea Fishes. Berlin: Springer Verlag; 1986. p. 49-62.

14. Bass AJ, Compagno LV. Families Echinorhinidae, Proscylliidae, Scyliorhinidae. In: Smith MM, Heemstra PC, editors. Smith's Sea Fishes. 63rd ed. Johannesburg: Macmillian; 1986. p. 87-95.

15. Compagno LV. FAO Species Catalogue. Vol. 4. Sharks of the World: An Annotated and Illustrated Catalogue of Shark Species Known to Date. Part 2. Carcharhiniformes. Rome: U.N. Food and Agriculture Organization; 1984. p. 251-655.

16. Garrick JAF. Studies on New Zealand Elasmobranchii. Part VII. The Identity of Specimens of Centrophorus from New Zealand. Transactions of the Royal Society of New Zealand. 1959:86(1):127-41.

17. Herman J. Die Selachier-Zähne aus der Maastricht Stufe von Hemmoor, Niederelbe (NW-Deutschland). Geologisches Jahrbuch Reihe A. 1982;61:29-159.

18. Pfeil FH. Zahnmorphologische Untersuchungen an Rezenten und Fossilen Haien der Ordnungen Chlamydoselachiformes und Echinorhiniformes. Palaeo Ichthyologica. 1983;1:1-315.

19. Maisey JG, Naylor GJP, Ward DJ. Mesozoic Elasmobranchs, Neoselachian Phylogeny and the Rise of Modern Elasmobranch Diversity. In: Arratia G, Tintori A, editors. Mesozoic Fishes 3-Systematics. Palaeoenvironments and Biodiversity. München: Verlag Dr. Friedrich Pfeil; 2004. p. 17-56.
20. Velez-Zuazo X, Agnarsson I. Shark tales: a molecular species-level phylogeny of sharks (Selachimorpha, Chondrichthyes). Mol Phylogenet Evol. 2011;58:207-17.

21. Naylor GJP, Caira JN, Jensen K, Rosana KAM, Straube N, Lakner C. Elasmobranch Phylogeny: A Mitochondrial Estimate Based on 595 Species. In: Carrier JC, Musick JA, Heithaus MR, editors. Biology of Sharks and Their Relatives. Boca Raton: CRC Press; 2012. p. 31-56.

22. Naylor GJP, Ryburn JA, Ferigo O, Lopez A. Phylogenetic Relationships Among the Major Lineages of Modern Elasmobranchs. In: Hamlett WC, editor. Reproductive Biology and Phylogeny of Chondrichthyes: Sharks, Batoids and Chimaeras. Enfield: Science Publishers; 2005. p. 1-25.

23. Straube N, Iglésias SP, Sellos DY, Kriwet J, Schliewen UK. Molecular Phylogeny and Node Time Estimation of Bioluminescent Lanternsharks (Elasmobranchii: Etmopteridae). Mol Phylogenet Evol. 2010;56:905-17.

24. Sorenson L, Santini F, Alfaro ME. The Effect of Habitat on Modern Shark Diversification. J Evol Biol. 2014;27(8):1536-48. doi:10.1111/jeb.12405.

25. Maisey JG. What is an 'elasmobranch'? The impact of palaeontology in understanding elasmobranch phylogeny and evolution. J Fish Biol. 2012;80(5):918-51. doi:10.1111/j.1095-8649.2012.03245.x.

26. Cappetta H, Adnet S. Discovery of the recent genus Trigonognathus (Squaliformes: Etmopteridae) in the Lutetian of Landes (southwestern France). Remarks on the teeth of the recent species Trigonognathus kabeyai. Paläontol Z. 2001;74(4):575-81.

27. Adnet S, Guinot G, Cappetta H, Welcomme JL. Oldest evidence of bramble sharks (Elasmobranchii, Echonorhinidae) in the Lower Cretaceous of southeast France and the evolutionary history of orbitostylic sharks. Cretac Res. 2012;35:81-7.

28. Claes JM, Nilsson DE, Straube N, Collin SP, Mallefet J. Iso-luminance counterillumination drove bioluminescent shark radiation. Sci Rep. 2014;4:4328.

29. Klug S, Kriwet J. Timing of deep-sea adaptation in dogfish sharks: insights from a supertree of extinct and extant taxa. Zool Scr. 2009;39:331-42. doi:10.1111/j.1463-6409.2010.00427.x.

30. Compagno LJV, Dando M, Fowler S. A field guide to the sharks of the world. London; Collins; 2005.

31. Claes JM, Mallefet J. Bioluminescence of Sharks: First Synthesis. In: Meyer-Rochow VB, editor. Bioluminescence in Focus - A Collection of Illuminating Essays. Kerala: Research Signpost; 2009. p. 51-65.

32. Li C, Hofreiter M, Straube N, Corrigan S, Naylor GJP. Capturing proteincoding genes across highly divergent species. Biotechniques. 2013;54:321-6. doi:10.2144/000114039.

33. Meyer B, Meusemann K, Misof B: MARE. MAtrix REduction - A tool to select optimized data subsets from supermatrices for phylogenetic inference. [https://www.zfmk.de/de/forschung/forschungszentren-und-gruppen/mare]

34. Misof B, Meyer B, von Reumont BM, Kück P, Misof K, Meusemann K. Selecting informative subsets of sparse supermatrices increases the chance to find correct trees. BMC Bioinformatics. 2013;14:348.

35. Stamatakis A. RAxML version 8: a tool for phylogenetic analysis and post-analysis of large phylogenies. Bioinformatics. 2014;30(9):1312-3. open access.

36. Lartillot N. PhyloBayes home page. [www.phylobayes.org].

37. Lartillot N, Lepage T, Blanquart S. PhyloBayes 3: a Bayesian software package for phylogenetic reconstruction and molecular dating. Bioinformatics. 2009;25(17):2286-8. doi:10.1093/bioinformatics/btp368.

38. Straube N, Li C, Claes JM, Corrigan S, Naylor GJP (2015). Data from: Molecular Phylogeny of Squaliformes and first Occurrence of Bioluminescence in Sharks. http://datadryad.org/review?doi=doi:10.5061/dryad.n3581

39. White WT, Vaz DFB, Ho H-C, Ebert DA, de Carvalho MR, Corrigan S, et al. Redescription of Scymnodon ichiharai Yano and Tanaka 1984 (Squaliformes: Somniosidae) from the western North Pacific, with comments on the definition of somniosid genera. Ichthyol Res. 2014. doi:10.1007/s10228-014-0430-y.

40. Drummond AJ, Ho S, Philipps M, Rambaut A. Relaxed phylogenetics and dating with confidence. PLOS Biol. 2006:4:88

41. Drummond AJ, Rambaut A. BEAST: Bayesian evolutionary analysis by sampling trees. BMC Evol Biol. 2007;7:214.

42. Harmon LJ, Weir JT, Brock CD, Glor RE, Challenger W. GEIGER: Investigating evolutionary radiations. Bioinformatics. 2009;24:129-31.

43. Alfaro ME, Santini F, Brock C, Alamillo H, Dornburg A, Rabosky DL, et al. Nine exceptional radiations plus high turnover explain species diversity in jawed vertebrates. PNAS. 2009;106(32):13410-4.

44. Claes JM, Krönström J, Holmgren S, Mallefet J. GABA inhibition of luminescence from lantern shark (Etmopterus spinax) photophores. Comp Biochem Physiol C. 2011;153:231-6. 
45. Claes JM, Mallefet J. The lantern shark's light switch: turning shallow water crypsis into midwater camouflage. Biol Lett. 2010;6:685-7.

46. Claes JM, Sato K, Mallefet J. Morphology and control of photogenic structures in a rare dwarf pelagic lantern shark (Etmopterus splendidus). J Exp Mar Biol Ecol. 2011;406:1-5.

47. Claes JM, Ho H-C, Mallefet J. Control of luminescence from pygmy shark (Squaliolus aliae) photophores. J Exp Biol. 2012;215(10):1691-9. doi:10.1242/ jeb.066704.

48. Renwart M, Delroisse J, Claes JM, Mallefet J. Cytological changes during luminescence production in lanternshark (Etmopterus spinax Linnaeus, 1758) photophores. Zoomorphology. 2015;134:107-16.

49. Herring PJ, Morin JG. Bioluminescence of Fishes. In: Herring PJ, editor. Bioluminescence in Action. New York: Academic; 1978. p. 273-329.

50. Claes JM, Dean MN, Nilsson DE, Hart NS, Mallefet J. A deepwater fish with 'lightsabers' - dorsal spine-associated luminescence in a counterilluminating lanternshark. Sci Rep. 2013;3:1308.

51. Davis MP, Holcroft NI, Wiley EO, Sparks JS, Smith WL. Species specific bioluminescence facilitates speciation in the deep Sea. Mar Biol. doi: 10.1007/s00227-014-2406-x

52. Naylor GJP, Caira JN, Jensen K, Rosana KAM, White WT, Last PR. A DNA sequence-based approach to the identification of shark and ray species and its implications for global elasmobranch diversity and parasitology. Bull Am Mus Nat Hist. 2012;367:1-262.

53. Straube N, White WT, Ho H-C, Rochel E, Corrigan S, Li C, Naylor GJP: A DNA sequence based identification checklist for Taiwanese chondrichthyans. In: Systematics and biodiversity of sharks, rays, and chimaeras (Chondrichthyes) of Taiwan. Edited by Carvalho MR de, Ebert DA, Ho H-C, White WT. Zootaxa 3752: $256-278$

54. Trimgalore [www.bioinformatics.babraham.ac.uk/projects/trim_galore]

55. Martin M. Cutadapt removes adapter sequences from high-throughput sequencing reads. EMBnet journal. 2011;17:10-2.

56. Simpson JT, Wong K, Jackman SD, Schein JE, Jones SJ, Birol I. ABySS: a parallel assembler for short read sequence data. Genome Res. 2009;19:1117-23.

57. Ebersberger I, Strauss S, von Haeseler A. HaMStR: profile hidden markov model based search for orthologs in ESTs. BMC Evol Biol. 2009;9:157.

58. Katoh K, Misawa K, Kuma K, Miyata T. MAFFT: a novel method for rapid multiple sequence alignment based on fast Fourier transform. Nuc Ac Res. 2002;30(14):3059-66. doi:10.1093/nar/gkf436. PMC 135756

59. Katoh K, Kuma K, Toh H, Miyata T. MAFFT version 5: improvement in accuracy of multiple sequence alignment. Nuc Ac Res. 2005;33(2):511-8. doi:10.1093/nar/gki198. PMC 548345.

60. Silvestro M. RAxMLGUI: a graphical front-end for RAxML. Org Divers Evol. 2012;12:335-7.

61. Pattengale ND, Alipour M, Bininda-Edmonds ORP, Moret BME, Stamatakis A. How many bootstrap replicates are necessary? J Comp Biol. 2010;17:337-54.

62. Lanfear R, Calcott B, Ho SYW, Guindon S. PartitionFinder: combined selection of partitioning schemes and substitution models for phylogenetic analyses. Mol Biol Evol. 2012;29(6):1695-701.

63. Lanfear R, Calcott B, Kainer D, Mayer C, Stamatakis A. Selecting optimal partitioning schemes for phylogenomic datasets: a comparison of clustering methods. BMC Evol Biol 2014, 14:82 doi:10.1186/1471-2148-14-82

64. Lartillot N, Philippe H. A Bayesian mixture model for acrosssite heterogeneities in the amino-acid replacement process. Mol Biol Evol. 2004:21:1095-109.

65. Lartillot N, Brinkmann H, Hervé P. Suppression of long-branch attraction artefacts in the animal phylogeny using a site-heterogeneous model. BMC Evol Biol. 2007;7 Suppl 1:S4. doi:10.1186/1471-2148-7-S1-S4.

66. Pradel A, Tafforeau P, Maisey JG, Janvier P. A New Paleozoic Symmoriiformes (Chondrichthyes) from the Late Carboniferous of Kansas (USA) and Cladistic Analysis of Early Chondrichthyans. PLoS ONE. 2011;6(9), e24938. doi:10.1371/journal.pone.0024938.

67. Sansom IJ, Davies NS, Coates MI, Nicoll RS, Ritchie A. Chondrichthyan-like scales from the middle Ordovician of Australia. Palaeontology. 2012;55:243-7.

68. Tracer v.1.6 [http://tree.bio.ed.ac.uk/software/tracer/]

69. Figtree v.1.6 [http://tree.bio.ed.ac.uk/software/figtree/]
70. R Core Team: R: A Language and Environment for Statistical Computing [http://www.R-project.org]

71. Ginter M, Hampe O, Duffin C. Handbook of Paleoichthyology, Vol. 3D, Chondrichthyes. Paleozoic Elasmobranchii: Teeth. Verlag Friedrich Pfeil: Munich; 2010.

72. Cappetta H. Handbook of Paleoichthyology, Vol. 3B, Chondrichthyes II. Mesozoic and Cenozoic Elasmobranchii: teeth. Verlag Friedrich Pfeil: Munich; 2004.

\section{Submit your next manuscript to BioMed Central and take full advantage of:}

- Convenient online submission

- Thorough peer review

- No space constraints or color figure charges

- Immediate publication on acceptance

- Inclusion in PubMed, CAS, Scopus and Google Scholar

- Research which is freely available for redistribution 